\title{
Lithium: The Wonder Drug of Psychiatry
}

\author{
R Hanwella
}

\section{Abstract}

The efficacy of lithium for treating the acute symptoms of mania, as well its use as a mood stabiliser is well established. However, lithium has a narrow therapeutic index and there is potential for fatal toxicity, as well as serious side effects including renal failure. Patient education is important, and psychiatrists need to spend time with their patients prior to starting lithium therapy. A psychiatrist with expert knowledge on lithium is a necessity for safe use of lithium. Unlike other major psychiatric disorders where there are equivalent alternatives, lithium by far is the best treatment for bipolar disorder. All patients with bipolar disorder, unless there are serious contraindications, must be offered the option of taking lithium.

SL J Psychiatry 2020; 11(2): 1-3
The Atacama Desert in Northern Chile is the world's driest place. At three million years, it is the oldest desert. In caverns underneath are pools of brine from an ancient sea. This is the world's major source of lithium. In 1817, the Swedish chemist Johan Arfwedson isolated lithium from petalite ore and the name lithium was derived from the Greek word lithos for stone. For the public, the primary use of lithium is in batteries powering mobile phones and cameras to motor cars. For the psychiatrist, lithium is a wonder drug that has revolutionised the treatment of bipolar disorder, a major psychiatric disorder afflicting nearly one percent of the adult population.

The British physician Alfred Garrod introduced lithium into medical practice in 1850 . He thought accumulation of uric acid caused gout and that lithium salts could help eliminate uric acid from the body (1). Lithium was used as far back as the $19^{\text {th }}$ century in psychiatry, but the Australian psychiatrist John Cade is credited with discovering the use of lithium for mania. John Joseph Cade, the father of lithium therapy in mood disorders, was born in 1912 in a small country town in Victoria, Australia. He postulated that mania might be a state of intoxication due to excess of an abnormal metabolite. To test his theory, he injected urine from patients with mania, depression and schizophrenia, into guinea pigs. He thought the urine of manic patients was the most toxic. He believed this substance was urea and decided to explore the effect of uric acid on the toxicity of urea. As uric acid was not readily soluble in water, he used lithium urate. Later he substituted another lithium salt, lithium carbonate, which he injected intraperitoneally in to guinea pigs. The results were remarkable, “After a latent period of about two hours the animals, although fully conscious, became extremely lethargic and unresponsive to stimuli for one to two hours before once again becoming normally active and timid (2).”

After testing lithium on himself, Cade concluded that it was without serious side effects and embarked on the first clinical trial of lithium. Perhaps by chance rather than by design, he chose the correct dose. Cade published the results of lithium therapy on 10 patients in his paper titled Lithium Salts in the Treatment of Psychotic Excitement in The Medical Journal of Australia's September 1949 issue (2). Most of his patients made a good recovery, but some relapsed because of noncompliance and the first patient treated by Cade later died of lithium toxicity.

After Cade's pioneering work, the study of lithium shifted from Australia to Denmark. Between 1952 and 1954, 40 patients with mania took part in a double-blind trial at the Psychiatric Hospital in Risskov. The trial confirmed that lithium was effective against mania. Later, a bipolar patient given long-term lithium therapy recovered from both his depressive and manic episodes. Thereafter a systematic trial by Danish psychiatrists Christian Baastrup and Mogens Schou clearly showed that lithium reduced the recurrence of manic and depressive episodes in patients with bipolar illness. Mogens Schou published his landmark trial in the Archives of General Psychiatry in 1967 (3). He would pioneer work on lithium in the next 40 years. 
Lithium is now firmly established as the first line of treatment for bipolar disorder. After more than half a century of use, exactly how lithium works is unclear but there are some plausible hypotheses. Bipolar disorder causes progressive worsening of cellular function called neuroprogression. Lithium is thought to slow down, stop or even reverse this deterioration. In bipolar disorder, overexcitation of dopaminergic and glutamatergic pathways with inhibition of GABAergic pathways may cause neuronal damage. Lithium counters these effects by inhibiting dopamine and glutamate pathways and increasing GABA levels. Lithium also promotes the release of neuroprotective proteins through GABA. Bipolar disorder causes structural and functional abnormalities in the fronto-limbic network, and patients have reduced grey matter in prefrontal cortex and anterior limbic regions (4). Effective lithium therapy repairs such structural defects in bipolar patients.

"The endless questioning finally ended. My psychiatrist looked at me, there was no uncertainty in his voice. 'Manic-depressive illness'. I admired his bluntness. I wished him locusts on his lands and a pox upon his house. Silent, unbelievable rage. I smiled pleasantly. He smiled back. The war had just begun”. This quote from An Unquiet Mind by Kay Jamison, a psychologist, and a sufferer from bipolar disorder, graphically captures the rage a patient might feel when told the diagnosis of bipolar disorder (5). Though it may be an uphill task to persuade patients to take lithium, there is little doubt that lithium by far is the best mood stabiliser for the treatment of bipolar disorder. For other major psychiatric disorders, the difference between optimum drugs are small but for bipolar disorder, lithium by a wide margin is the best.

Psychiatrists are reluctant to prescribe lithium, and patients reluctant to take it. There are several reasons. Lithium has a narrow therapeutic index. To prevent toxicity patients need to know situations leading to dehydration such as fever, vomiting and diarrhoea. Some common drugs used for other medical conditions such as diuretics, ACE inhibitors and NSAIDs can increase lithium levels (3). Lithium toxicity is serious and potentially lethal. Psychiatrists also fear potential renal damage with long-term use. As for patients, the prospect of taking a medication lifetime is not appealing. The initial side effects such as tremor though not dangerous are troubling. Hair loss and acne, especially in females, are major reasons for noncompliance. But it is the responsibility of every psychiatrist to vigorously try and persuade patients with bipolar disorder to start and continue lithium long term.

Potential for renal damage is an importance concern with long-term lithium therapy. A review in 2010 showed that the number needed to treat for severe kidney damage was 300, meaning that you have to treat 300 patients with lithium before one patient develops kidney toxicity who wouldn't have developed it if they were never treated with lithium. This is not a huge number, but it is significant (6). To avoid renal toxicity, there are a few basic precautions the clinician can take. Lithium levels should be kept below $1.0 \mathrm{mEq} / \mathrm{L}$ at all times and maintenance levels at $0.75 \mathrm{mEq} / \mathrm{L}$ or less. There is evidence that levels below $0.5 \mathrm{mEq} / \mathrm{L}$ are not effective, but this may differ in individual patients. Patients should be informed about causes of increased lithium levels. Serum creatinine levels and eGFR should be monitored every six months or every four months in high-risk patients such the elderly and those with impaired renal functions. Switching to a once a day dose of lithium even if using the short-acting formulation allows time for the kidney to recover without impairing drug efficacy. If serum creatinine levels creep up over $1.4 \mathrm{mg} / \mathrm{dl}$ (some say 1.6) lithium should be stopped or advice sought from a nephrologist. Another reason to do so would be if there are three consecutive increases in serum creatinine. Again, if the eGFR drops below $60 \mathrm{ml} / \mathrm{min}$ consider stopping lithium and switching to alternate treatments (7). If these precautions are observed there is little risk of a patient progressing to end stage renal failure. As patients on lithium are monitored regularly it is also likely that kidney failure due to other causes will be detected earlier in these patients.

Another issue with long-term lithium therapy, though not life threatening, is hypothyroidism. Lithium inhibits the release of thyroxine and thereby increases thyroid stimulating hormone (TSH). Elevated TSH may be associated with rapid cycling, especially in women, goitre, weight gain and depression. TSH levels should be monitored every six months, and thyroxine supplementation started if levels are high. What would be considered high? Endocrinologists would not consider treating at levels below five but some studies have suggested that for bipolar patients, and patients with depression TSH levels above two should be treated with thyroxine (7).

It takes time and expertise to correctly diagnose bipolar disorder and treat with lithium. But lithium is the best drug we have to treat this condition, and it is the responsibility of the health care professional to acquire the necessary expertise and give all patients diagnosed with bipolar illness the opportunity to be treated with lithium. Otherwise you would have done them a great disservice. As Kay Jamison said in Unquiet Mind, "No matter what struggles I had had with lithium, it was painfully clear to me that without it I would have been long dead or on the back wards of a state hospital" (5). Lithium is indeed a wonder drug of psychiatry.

\section{Conflicts of interest}

None declared. 
Prof Raveen Hanwella, Department of Psychiatry, Faculty of Medicine, University of Colombo and Hon Consultant Psychiatrist, National Hospital of Sri Lanka

Corresponding Author: R Hanwella

Email: raveenhanwella@psych.cmb.ac.lk

iD http://orcid.org/0000-0002-3020-0316

\section{References}

1. Johnson FN. The history of lithium therapy. $1^{\text {st }}$ ed. UK: Palgrave Macmillan, 1984.
2. Cade JF. Lithium salts in the treatment of psychotic excitement. Med J Aust. 1949; 2(10): 349-525.

3. Mogens S. Lithium treatment of mood disorders. $6^{\text {th }}$ ed. Karger, 2004.

4. Malhi GS, Masson M, Bellivier F. The science and practice of lithium therapy. Springer, 2013.

5. Jamison KR. An unquiet mind: a memoir of moods and madness. Vintage, 1996.

6. Bendz1 H, Schon, Attman P, Aurell M. Renal failure occurs in chronic lithium treatment but is uncommon. Kidney Int 2010; 77(3): 219-24.

7. Shine B, McKnight RF, Leaver L, Geddes JR. Long-term effects of lithium on renal, thyroid, and parathyroid function: a retrospective analysis of laboratory data. Lancet 2015; 386: 461-68. 